\title{
Aortic dissection, a diagnostic challenge
}

\author{
W. W. Jansen Klomp' • A. P. Nierich ${ }^{2}$ A. W. J. van 't Hof ${ }^{1}$
}

Published online: 25 July 2017

(c) The Author(s) 2017. This article is an open access publication.

\section{To the Editor,}

We recently published a study in which we showed that acute aortic dissection (AAD) is often initially missed, which was contributable to the absence of a typical clinical profile [1]. In addition to our findings, Siniorakis and colleagues stress the importance of fever as an often overlooked sign of AAD.

The body temperature on admission was not incorporated in our database, as such we cannot give information on this topic with regards to our cohort. Following the scarce literature we agree, however, with the points stressed by Siniorakis. Indeed, data from the International Registry of Acute Aortic Dissections (IRAD) have shown that fever was an independent predictor of a delayed diagnosis, with a median time from admission to diagnosis of $32 \mathrm{vs} .4 \mathrm{~h}$ [2]. Although fever is usually an inflammatory response to the dissection itself, it may also precede $\mathrm{AAD}$ in the rare case of complicated aortitis.

It is important for physicians in the emergency care department to be aware that fever may be a sign of AAD, which should not distract from the important diagnostic work-up for AAD.
Open Access This article is distributed under the terms of the Creative Commons Attribution 4.0 International License (http:// creativecommons.org/licenses/by/4.0/), which permits unrestricted use, distribution, and reproduction in any medium, provided you give appropriate credit to the original author(s) and the source, provide a link to the Creative Commons license, and indicate if changes were made.

\section{References}

1. Jansen Klomp WW, Brandon Bravo Bruinsma GJ, Peelen LM, Nierich AP, Grandjean JG, van't Hof AWJ. Clinical recognition of acute aortic dissections: insights from a large single-centre cohort study. Neth Heart J. 2017;25(3):200-6. doi:10.1007/s12471-0160921-8.

2. Harris KM, Strauss CE, Eagle KA, et al. Correlates of delayed recognition and treatment of acute type A aortic dissection. Circulation. 2011;124(18):1911-8. doi:10.1161/circulationaha.110. 006320 .
Response to the letter from Siniorakis et al: Fever as a first manifestation of acute aortic dissection. DOI 10.1007/s12471016-0921-8

\footnotetext{
$\triangle$ A. W. J. van 't Hof

v.r.c.derks@isala.nl

1 Department of Cardiology, Isala, Zwolle, The Netherlands

2 Department of (Thoracic) Anaesthesia and Intensive Care, Isala, Zwolle, The Netherlands
} 


\title{
Advertisement placed here.
}

\author{
SCS bohn \\ stafleu \\ CL van loghum \\ Springer Media
}

Houten 2017 